Solid Freeform Fabrication 2018: Proceedings of the 29th Annual International Solid Freeform Fabrication Symposium - An Additive Manufacturing Conference

\title{
EFFCT OF SPRAY-BASED PRINTING PARAMETERS ON CEMENTITIOUS MATERIAL DISTRIBUTION
}

\author{
Bing Lu ${ }^{1,2}$, Mingyang $\mathrm{Li}^{* 1}$, Wenxin Lao ${ }^{1}$, Yiwei Weng ${ }^{1,2}$, Shunzhi Qian ${ }^{1,2}$, Ming Jen Tan ${ }^{1}$, \\ Kah Fai Leong ${ }^{1}$ \\ ${ }^{1}$ Singapore Centre for 3D Printing, School of Mechanical and Aerospace Engineering, \\ Nanyang Technological University, Singapore 639798 \\ ${ }^{2}$ School of Civil and Environmental Engineering, Nanyang Technological University, \\ Singapore 639798
}

\begin{abstract}
In the past decade, 3D printing is getting into more and more industry areas including building and construction. However, most 3D cementitious material printing processes are limited in horizontal printing surface. Due to the nature of building and construction industry, $3 \mathrm{D}$ spray cementitious material printing process was developed to apply material in vertical or even overhang surfaces. Unlike traditional manually operated spray method in building and construction industry, 3D spray cementitious material printing process requires higher accuracy on material distribution. In this paper, the effects of four printing parameters (cementitious material flow rate, air flow rate, nozzle travel speed, nozzle standoff distance) on material distribution in 3D spray cementitious material printing process were investigated experimentally. An experimental model, which can be further used in the control of 3D spray cementitious material printing process, was then developed upon on the results.
\end{abstract}

Keywords: Additive manufacturing, 3D cementitious material printing, spray, material distribution, modelling

\section{Introduction}

3D printing, also known as additive manufacturing, is a method to sequentially deposit material layer by layer to fabricate desired objects [1]. Recently, remarkable progress of 3D printing has been seen in building and construction industry. Large computer-controlled gantry printing systems, e.g. Contour Crafting [2], Concrete Printing [3] have been successfully developed to print cementitious materials. On the other hand, the precise movement control of robotics contributed to robot-based printing systems [4] [5], which have less size limitation of printed structure compared with gantry printing system. The successful practices of these printing systems stimulate the corresponding material research. Le et al. [6] proposed several key properties for high performance printable cementitious materials, e.g. pumpability and buildability. Subsequent research studies [7] [8] [9] [10] further revealed that pumpability and buildability are closely related to rheological properties of the material. With these material development guidance, functional printable cementitious materials have been invented, e.g. 3D printable sustainable material [11], 3D printable fiber reinforced concrete material [12] [13].

Most 3D printing in the building and construction is extrusion-based, and the shape of extrudate can be effectively controlled by the design of nozzle outlet [14], nozzle standoff height [15], printing speed [16], etc. However, there is little study of 3D cementitious material printing on the vertical surface, e.g. printing of vertical decorative pattern. Different from

\footnotetext{
*limingyang@ntu.edu.sg
} 
printing on the horizontal surface, the vertically deposited material needs to resist the shear induced by gravity. In the building and construction area, the conventional solution is the adoption of spraying concrete materials. However, due to the lack of systematic control of spray and large rebound of high-speed sprayed material at far distance, the sprayed material on the substrate is not uniformly distributed and needs subsequent manual scraping work [17]. In contrast, 3D spray cementitious material printing process requires higher accuracy on the material distribution without human intervention. However, there is very limited study on 3D sprayable cementitious materials [18], and no research has been carried focusing on material distribution of 3D spray cementitious material printing. The situation stimulates the research motivation for this paper.

The material distribution of 3D spray cementitious material printing is systematically studied in this paper. Similar to extrusion-based 3D cementitious material printing, material distribution may vary with different printing parameters. The effects of four printing parameters on sprayed material distribution have been investigated, i.e. cementitious material flow rate, air flow rate, nozzle travel speed, and nozzle standoff distance. An experimental model of material distribution is hereby proposed, which can be utilized for further study of 3D spray cementitious material printing.

\section{Material Design}

The sprayable cementitious material used in the experiments was composed of Type-I ordinary Portland cement (OPC), Class-F fly ash, silica fume, sand and tap water. The grading curve of river sand is shown in Figure 1. Superplasticizer of $1 \mathrm{~g}$ and Air entraining agent (AEA) of $0.1 \mathrm{~g}$ was added to per liter mix. The mix proportion of the sprayable cementitious material is shown in Table 1.

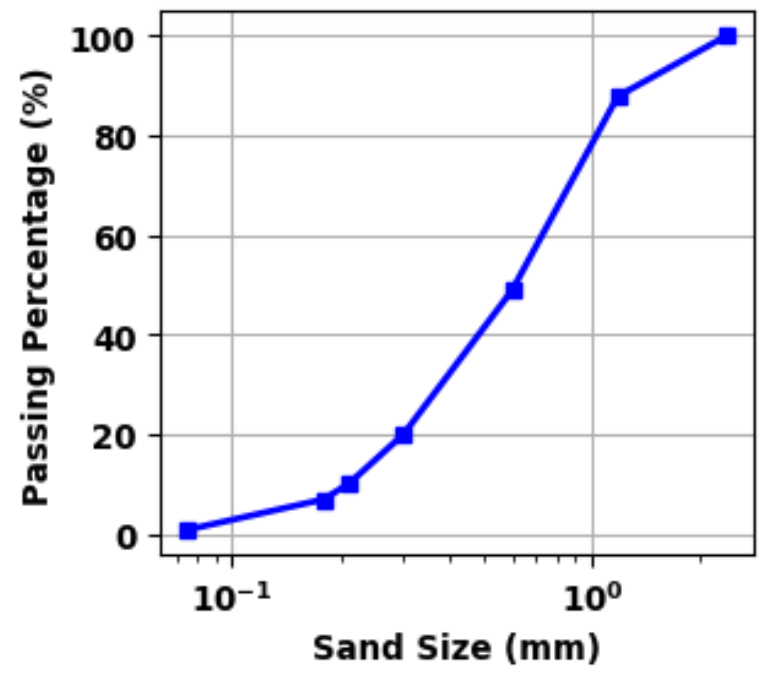

Figure 1 Sand gradation 
Table 1 Mix mass proportion of the sprayable cementitious material

\begin{tabular}{ccccccc}
\hline Cement & $\begin{array}{c}\text { Sand / } \\
\text { Cement } \\
\text { Ratio }\end{array}$ & $\begin{array}{c}\text { Fly ash / } \\
\text { Cement } \\
\text { Ratio }\end{array}$ & $\begin{array}{c}\text { Silica fume } \\
\text { / Cement } \\
\text { Ratio }\end{array}$ & $\begin{array}{c}\text { Water / } \\
\text { Cement } \\
\text { Ratio }\end{array}$ & $\begin{array}{c}\text { Super- } \\
\text { plasticizer }\end{array}$ & AEA \\
\hline 1 & 0.45 & 0.5 & 0.05 & 0.62 & $1 \mathrm{~g} / \mathrm{L}$ & $0.1 \mathrm{~g} / \mathrm{L}$ \\
\hline
\end{tabular}

The sprayable cementitious material was prepared in Hobart HL-200 mixer as per following procedure. Weighed raw ingredients except water, AEA and superplasticizer were mixed for 180s at slow speed. The water with dissolved AEA was added afterwards and mixed with other ingredients for another 180s at slow speed. Then superplasticizer was added to the mixture, firstly mixed for 90s at slow speed and followed by another 90 s mixing at high speed. Then the material was taken for the experiments.

Some key fresh properties were assessed to check the pumping performance of the designed sprayable cementitious material. The flowability loss of the fresh sprayable cementitious material was traced by the flow table test, which provides flow diameter of the material after the slump cone is lifted and stroke for 25 strikes [19]. As shown in the Figure 2, there is no sudden decrease of flowability within one hour. The viscosity of fresh cementitious material can be described by Bingham Plastic model, and the yield stress and plastic viscosity were measured using Viskomat rotational rheometer, of which values are $115.18 \mathrm{~Pa}$ and 20.27 $\mathrm{Pa} \cdot \mathrm{s}$ respectively. Pumpability test with printing delivery system showed that the material with such rheological parameters can be pumped consecutively.

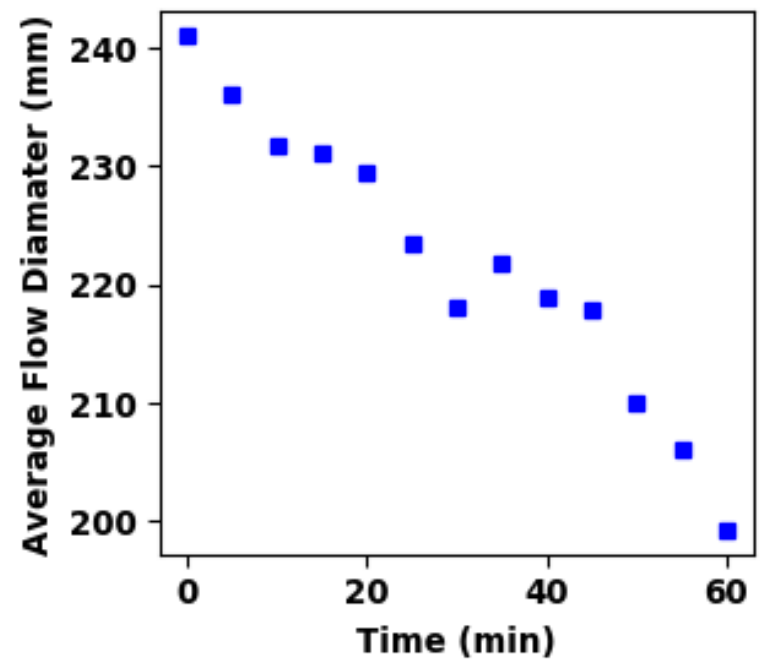

Figure 2 Average flow diameter with time

\section{Experiment Design}

The 3D spray cementitious material printing experiments were designed to be completed with robotic arm control. The robotic arm used in the experiments is ABB IRB1600 robotic arm with 1.45 m reach. MAI Pictor Pump was adopted for pumping material through a hose of $2.5 \mathrm{~m}$ in length and $25.4 \mathrm{~mm}$ in diameter. High pressure air was connected from lab vessel with a hose of $5 \mathrm{~m}$ in length and $12.7 \mathrm{~mm}$ in diameter. The spray nozzle 
connected to the cementitious material and high pressure air hoses was attached to the end of robotic arm. The whole setup of equipment can be referred to in Figure 3.

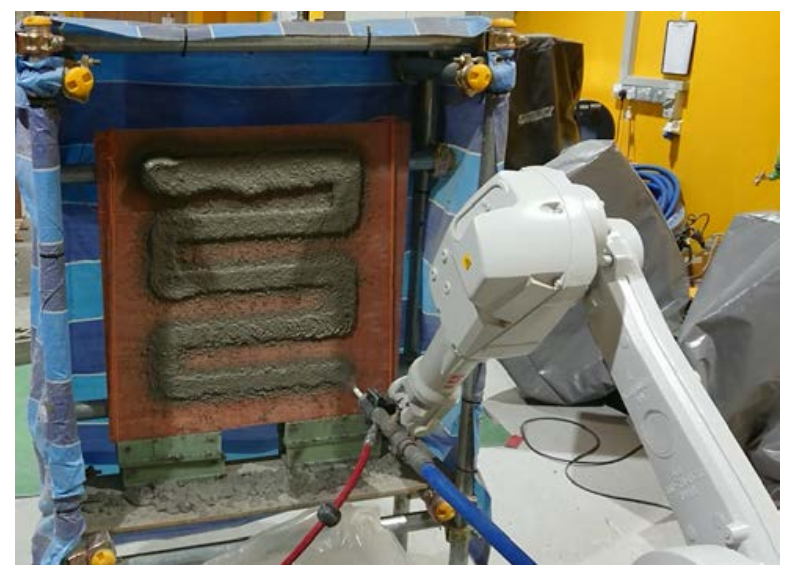

Figure 3 Experiment setup consist of robotic arm, cementitioul pump with hose and high pressure air

The nozzle's orientation and position can be controlled by the movement of robotic arm as per designed programme. The spray nozzle is adjusted to point perpendicularly to the vertical substrate in the 3D spray cementitious material printing process. The nozzle travel path is illustrated in Figure 4. In the experiments, the nozzle travels parallel to the substrate plane at five different speeds to spray straight filaments, i.e. $50 \mathrm{~mm} / \mathrm{s}, 100 \mathrm{~mm} / \mathrm{s}, 150 \mathrm{~mm} / \mathrm{s}, 200 \mathrm{~mm} / \mathrm{s}$ and $250 \mathrm{~mm} / \mathrm{s}$. The distances between spray nozzle and the substrate were set as three different values in different runs of experiments, i.e. $50 \mathrm{~mm}, 70 \mathrm{~mm}$ and $100 \mathrm{~mm}$.

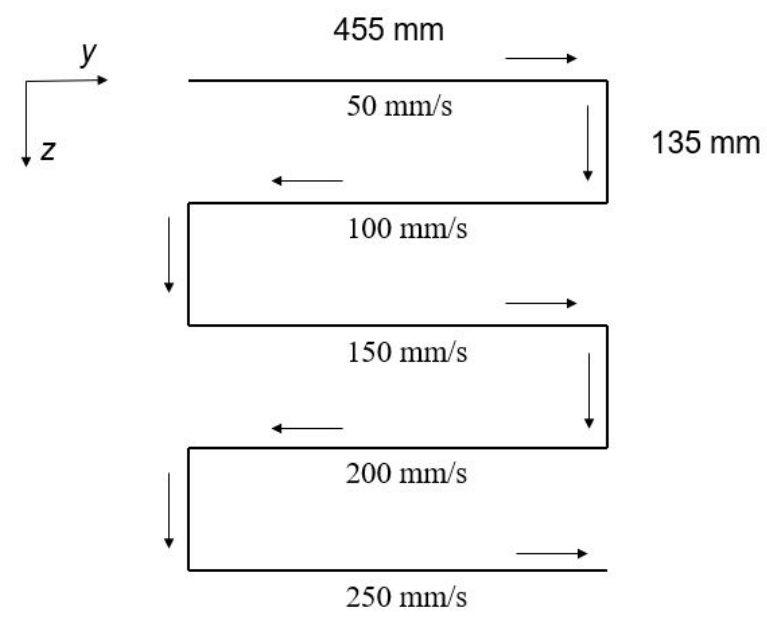

Figure 4 Nozzle travel path with different travel speeds

In addition to the nozzle position and travel speed controlled by robotic arm, cementitious material flow rates and air flow rates were also set to have different levels in the experiments. The cementitious material flow rate is roughly proportional to the pump speeds, which were set as $600 \mathrm{rpm}$ and $1200 \mathrm{rpm}$ in experiments. Air flow rates can be identified by 
air inject pressure values, which were 0.5 Bar and 1.0 Bar in experiments. The complete experiment design table is shown in Table 2.

Table 2 Experiment design table

\begin{tabular}{ccccc}
\hline Group & $\begin{array}{c}\text { Pumping rate } \\
(\mathrm{rpm})\end{array}$ & $\begin{array}{c}\text { Air inject } \\
\text { pressure } \\
\text { (bar) }\end{array}$ & $\begin{array}{c}\text { Nozzle standoff } \\
\text { distance }(\mathrm{mm})\end{array}$ & $\begin{array}{c}\text { Nozzle travel speed } \\
(\mathrm{mm} / \mathrm{s})\end{array}$ \\
\hline A & 600 & 0.5 & 50 & $50 \sim 250$ \\
B & 600 & 0.5 & 70 & $50 \sim 250$ \\
C & 600 & 0.5 & 100 & $50 \sim 250$ \\
D & 1200 & 0.5 & 50 & $50 \sim 250$ \\
E & 1200 & 0.5 & 70 & $50 \sim 250$ \\
F & 1200 & 0.5 & 100 & $50 \sim 250$ \\
G & 1200 & 1.0 & 50 & $50 \sim 250$ \\
H & 1200 & 1.0 & 70 & $50 \sim 250$ \\
I & 1200 & 1.0 & 100 & $50 \sim 250$ \\
\hline
\end{tabular}

After completion of 3D spray cementitious material printing process, the sprayed filaments were covered with plastic sheet for 24 hours in the lab. This guarantees the sprayed filaments have enough strength to be scraped from the substrate without deformation. Three samples were cut from the centre of each sprayed filament to expose the cross section (see Figure 5). The length of each sample is $30 \mathrm{~mm}$. The images of cross section were processed and analysed by MATLAB. Detailed process of image analysis can be found in Lao et al. [14].
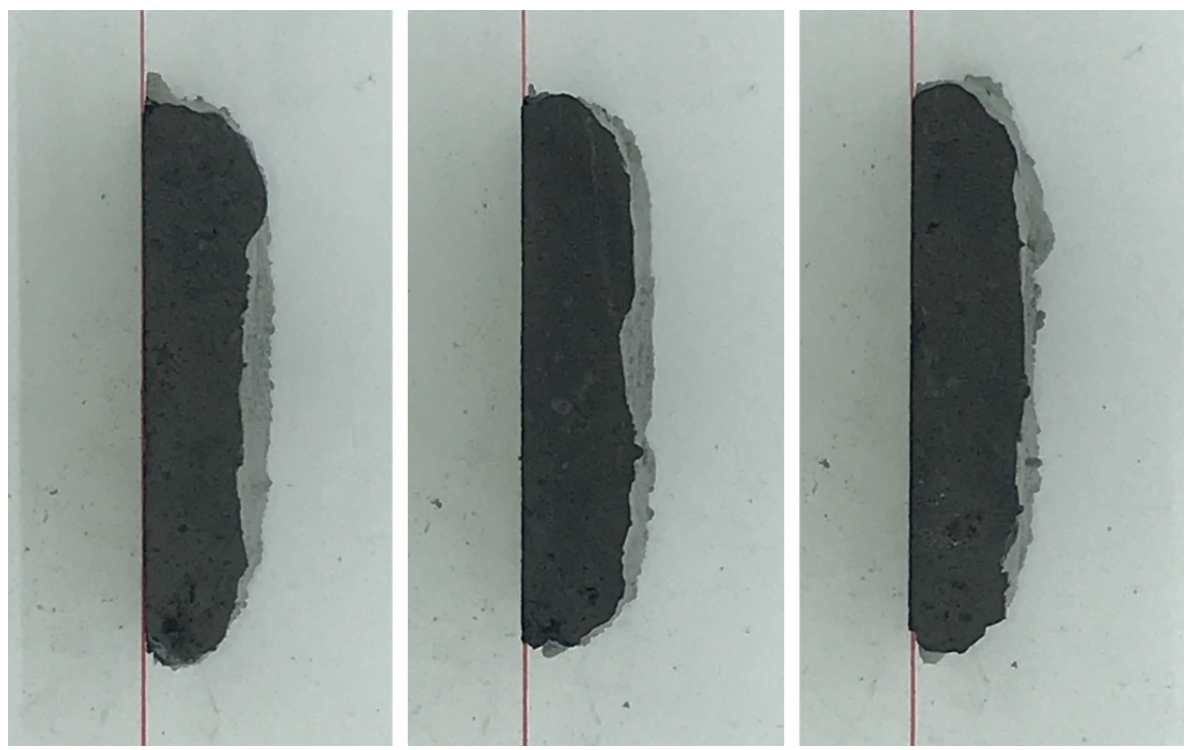

Figure 5 Exposed corss sections of three samples cut from sprayed filament

\section{Results and Discussions}

Thickness distribution with respect to filament width is used to describe the distribution of sprayed materials. A uniform material distribution should have nearly constant thickness, i.e. the cross section approaches rectangular shape. The integration of thickness distribution is 
the cross section area, which suggests how much material is sprayed. The thickness distribution of experiment groups A to I are shown in Figure 6. It has to be pointed out that, due to very thin thickness of sprayed filaments, no data was collected for experiment group C. The integrated cross section area values are shown in Figure 7.
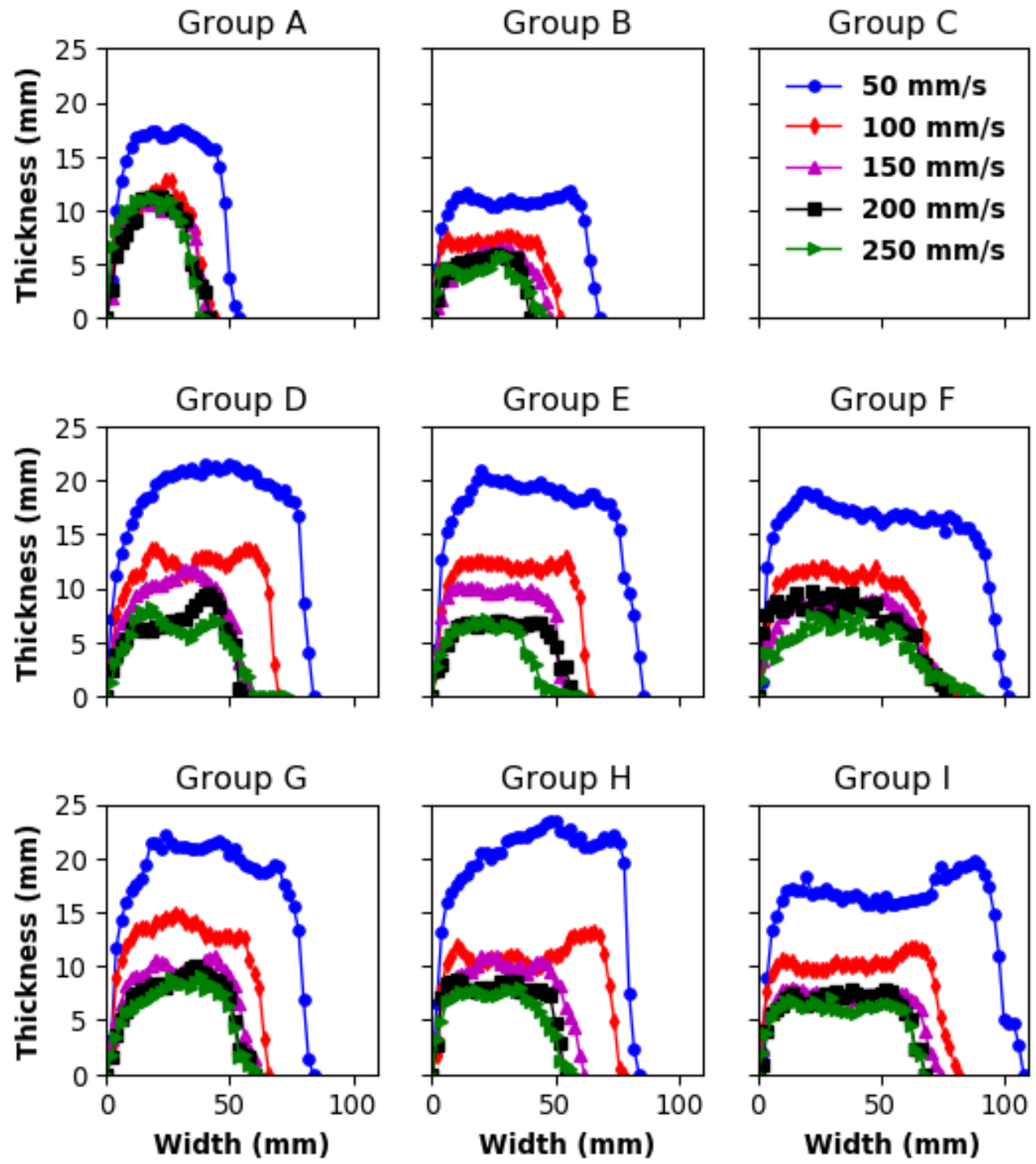

Figure 6 Thickness Distribution (Group A to Group I) 


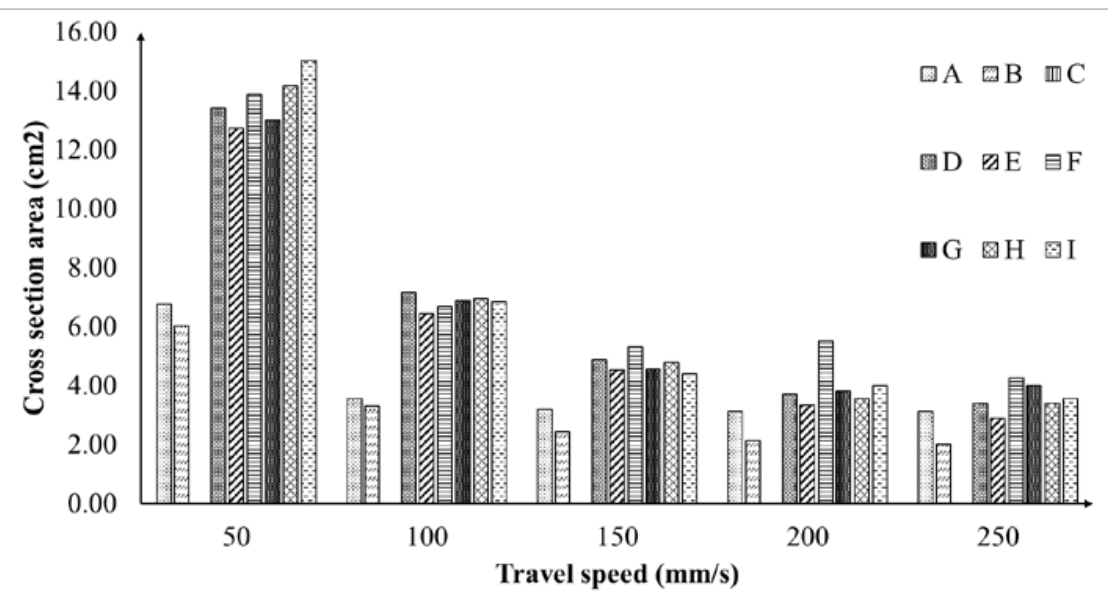

Figure 7 Cross section area at different travel speeds in each group

There are some general characteristics in the material distribution. It can be found that increased pump speed can greatly increase the width and thickness of sprayed filament. However, there is no significant difference in width and thickness when air flow rate increases. The increase of nozzle travel speed decreases the thickness of sprayed filament, especially when the nozzle travel speed increases from $50 \mathrm{~mm} / \mathrm{s}$ to $100 \mathrm{~mm} / \mathrm{s}$. Nevertheless, the thickness difference is not significant when the speed is higher than $100 \mathrm{~mm} / \mathrm{s}$ in Group A and B; for other groups when the speed is higher than $150 \mathrm{~mm} / \mathrm{s}$ the thickness difference also decreases. Larger standoff distance can enlarge the thickness difference and also increase the width of sprayed filament. In addition, larger standoff distance leads to smaller thickness.

Figure 7 shows cross section area greatly increases with higher pumping rate, especially when the nozzle travel speed is smaller than $200 \mathrm{~mm} / \mathrm{s}$. Similar to the trend of thickness distribution, there is little difference of cross section area when the nozzle travels at high speed. The phenomenon can be attributed to the discontinuity in the pumping process, which is traced from decreased density of sprayed filaments as shown in Table 3. On the other hand, either based on cross section area or density data, air flow rate does not seem to significantly contribute to material distribution.

Table 3 Density of sprayed filaments $\left(\mathrm{g} / \mathrm{cm}^{3}\right)$

\begin{tabular}{cccccccccc}
\hline $\begin{array}{c}\text { Travel } \\
\text { speed } \\
(\mathrm{mm} / \mathrm{s})\end{array}$ & A & B & C & D & E & F & G & H & I \\
\hline 50 & 1.64 & 1.65 & $/$ & 1.67 & 1.79 & 1.62 & 1.64 & 1.67 & 1.54 \\
100 & 1.40 & 1.47 & $/$ & 1.57 & 1.64 & 1.54 & 1.57 & 1.59 & 1.59 \\
150 & 1.39 & 1.23 & $/$ & 1.52 & 1.58 & 1.39 & 1.61 & 1.52 & 1.59 \\
200 & 1.23 & 1.05 & $/$ & 1.39 & 1.46 & 1.14 & 1.48 & 1.60 & 1.45 \\
250 & 1.34 & 0.98 & $/$ & 1.26 & 1.20 & 0.99 & 1.36 & 1.40 & 1.49 \\
\hline
\end{tabular}

Table 4 and Table 5 show volume flow rate and mass flow rate of each group respectively. As nozzle travel speed increases, the volume flow rate increases while the mass flow rate remains similar when travel speed is smaller than $200 \mathrm{~mm} / \mathrm{s}$. With the same travel speed (lower than $200 \mathrm{~mm} / \mathrm{s}$ ), it can be found that both volume flow rate and mass flow rate 
increase proportionally as cementitious material flow rate increases. In contrast, when the nozzle travels at high speed, volume flow rate and mass flow rate increase. Further investigation needs to be taken to study the mechanism of this transition.

Table 4 Volume flow rate of experiments $(\mathrm{mL} / \mathrm{s})$

\begin{tabular}{cccccccccc}
\hline $\begin{array}{c}\text { Travel } \\
\text { speed } \\
(\mathrm{mm} / \mathrm{s})\end{array}$ & A & B & C & D & E & F & G & H & I \\
\hline 50 & 33.89 & 30.16 & $/$ & 67.06 & 63.63 & 69.38 & 64.99 & 70.84 & 75.21 \\
100 & 35.56 & 33.01 & $/$ & 71.69 & 64.55 & 66.80 & 68.94 & 69.48 & 68.44 \\
150 & 48.03 & 36.38 & $/$ & 73.06 & 68.12 & 79.74 & 68.49 & 71.70 & 66.06 \\
200 & 62.70 & 42.54 & $/$ & 74.23 & 66.88 & 110.58 & 76.57 & 71.26 & 80.25 \\
250 & 78.01 & 50.36 & $/$ & 84.93 & 72.49 & 106.64 & 100.05 & 85.27 & 89.20 \\
\hline
\end{tabular}

Table 5 Mass flow rate of experiments (g/s)

\begin{tabular}{cccccccccc}
\hline $\begin{array}{c}\text { Travel } \\
\text { speed } \\
(\mathrm{mm} / \mathrm{s})\end{array}$ & A & B & C & D & E & F & G & H & I \\
\hline 50 & 55.61 & 49.67 & $/$ & 112.22 & 114.06 & 112.06 & 106.39 & 118.00 & 116.06 \\
100 & 49.67 & 48.56 & $/$ & 112.44 & 105.78 & 102.56 & 108.11 & 110.22 & 109.00 \\
150 & 66.83 & 44.67 & $/$ & 111.17 & 107.50 & 111.00 & 110.17 & 108.83 & 104.83 \\
200 & 77.11 & 44.67 & $/$ & 103.33 & 97.56 & 125.67 & 113.56 & 114.00 & 116.67 \\
250 & 104.72 & 49.44 & $/$ & 107.22 & 87.22 & 105.83 & 135.83 & 119.72 & 132.50 \\
\hline
\end{tabular}

\section{Construction of Empirical Model}

There is limited study on the distribution of sprayed materials. Ginouse and Jolin proposed a second-order Gaussian distribution model to describe the mass distribution of conventional sprayed concrete materials when the spray nozzle does not move [20]. In this case, the sprayed pattern has central symmetry, and more material is gathered around the centre part. The second-order Gaussian distribution model can be expressed as Eq. (1) and Eq. (2) in polar coordination system. The origin is the nodal by central axis of spray nozzle and substrate.

$$
\begin{aligned}
& j_{p}(r)=\left\{\begin{array}{cc}
j_{\max } F\left(\frac{r}{r_{\max }}\right) & r \leq r_{\max } \\
0 & r>r_{\max }
\end{array}\right. \\
& F\left(\frac{r}{r_{\max }}\right)=a_{1} \exp \left(-\frac{r / r_{\max }-a_{2}}{a_{3}}\right)+b_{1} \exp \left(-\frac{r / r_{\max }-b_{2}}{b_{3}}\right)
\end{aligned}
$$

where $r_{\max }$ is the maximum radius of sprayed material, $j_{\mathrm{p}}(r)$ is the mass flux density at radius $r$, and $j_{\max }$ is the maximum mass flux density that can be measured. The coefficient $a_{1}, a_{2}, a_{3}$, $b_{1}, b_{2}, b_{3}$ in Eq. (2) can be decided by experiment data. Mass flux density refers to the mass flow rate for infinitesimal area, so mass flow rate $Q(\mathrm{~kg} / \mathrm{s})$ can be expressed as Eq. (3). Mass flux density can also be estimated experimentally by sampling of sprayed material. 


$$
Q=2 \pi \int_{0}^{r_{\max }} r j_{p}(r) d r
$$

The experiments carried by Ginouse and Jolin showed that their proposed second-order Gaussian distribution model has good fit with experiment data when spray nozzle is placed 0.5 $\mathrm{m}$ and $1 \mathrm{~m}$ away from substrate. Refer to the good fit results of conventional spray concrete, the empirical model of 3D spray cementitious material printing may be constructed on this basis. Nevertheless, significant differences have to be taken into consideration. Firstly, the linear movement of spray nozzle make the sprayed pattern lose central symmetry. As the cross sections are vertical to the nozzle movement direction, the movement of nozzle should not affect material distribution in cross section planes. Secondly, the nozzle is placed much nearer to the substrate as per application of 3D spray printing. Therefore, the expectation of material distribution is first-order Gaussian distribution with some modifications. However, the experiment results in Figure 6 greatly deviate from Gaussian distribution. Thus the empirical model to describe 3D spray cementitious material printing cannot be constructed on the basis of Gaussian distribution.

There were three steps to construct the empirical material distribution model. The first step was to check the significances of printing parameters on the maximum width of sprayed filament by statistics model. The second step was considering the considering the physical deposition process and find the relationship between printing parameters and the maximum filament width. The third step was to correlate material distribution with width and average thickness data. In this step, the material distribution was described by three linear functions. Least square method was then utilized to construct the parameters of fitting functions.

From experiment results, it is suspected that air flow rate does not have significant effect on material distribution. Hence, statistical checking was carried to validate this suspect. Table 6 shows p-values of printing parameters for checking their correlation with width and maximum thickness of sprayed filaments. The confidence interval is $95 \%$. The p-values of air inject pressure exceed 0.05 significantly in each case, which certifies that air flow rate does not have significant effect on material distribution. In contrast, all the other p-values are greatly smaller than 0.05 , suggesting the other three printing parameters have significant effects on material distribution. Therefore, air flow rate will not be included in the empirical model.

Table 6 p-values of printing parameters

\begin{tabular}{ccc}
\hline Printing parameters & p-value for width & p-value for maximum thickness \\
\hline Pumping rate & $1.23 \times 10^{-6}$ & 0.02 \\
Air inject pressure & 0.58 & 0.72 \\
Nozzle travel speed & $3.09 \times 10^{-6}$ & $1.25 \times 10^{-10}$ \\
Standoff distance & $1.02 \times 10^{-4}$ & 0.02 \\
\hline
\end{tabular}

Considering the physics of the spray and deposition processes. When the material is sprayed out from nozzle, the spray angle can be considered as constant. Therefore, the maximum width of filament should be linearly related to the standoff distance. At the other hand, the maximum width of filament should be proportional to the square root of filament cross section area, which is proportional to the ratio between pumping flow rate and nozzle travel speed. Denote pumping rate as $\alpha(\mathrm{rpm})$, nozzle travel speed as $\gamma(\mathrm{mm} / \mathrm{s})$ and standoff distance as $\delta(\mathrm{mm})$, the function to describe the maximum width of sprayed filament $w(\mathrm{~mm})$ should be in the following expression: 


$$
w_{\max }=C_{1} \delta \sqrt{\frac{\alpha}{\gamma}}+C_{2}
$$

where $C_{1}$ and $C_{2}$ are constants depend on the pump, nozzle and material properties. Fitting experimental maximum filament widths into the proposed model, the proposed model described by

$$
w_{\max }=0.145 \delta \sqrt{\frac{\alpha}{\gamma}}+33.9
$$

The comparison between experimental results and this fitted model is shown in Figure 8, the coefficient of determination $R^{2}$ is 0.752 , suggesting this model has some rationality while still needs some improvement.

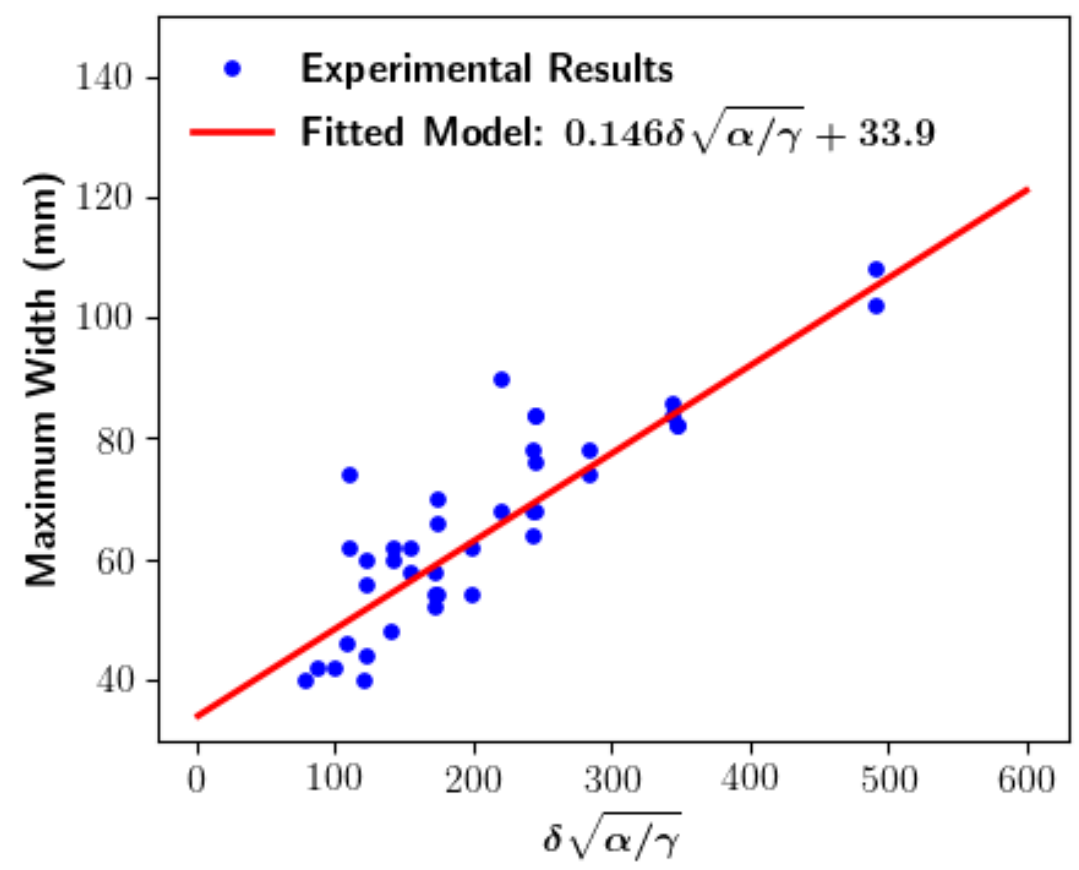

Figure 8 Comparison between experimental maximum width and fitted model.

The next step of constructing empirical model is to correlate material distribution with width and average thickness data. By observation, the non-dimensional thickness distribution of printed filament can be roughly described by a trapezoid model

$$
s(x, a, b, c)=\left\{\begin{array}{cc}
a x & 0 \leq x \leq b / a \\
b & b / a<x \leq 1-b / c \\
c(1-x) & 1-b / c<x \leq 1
\end{array}\right.
$$

where $x=w / w_{\max }$ is the non-dimensional filament width coordinate, $s=h w_{\max } /(\alpha / \gamma)$ is the nondimensional filament thickness coordinate, $a, b$, and $c$ are parameters which can be found by curve fitting. One fitting example is shown in Figure 9. All fitted parameters of experiment groups A to I are plotted in Figure 10. It is very difficult to draw any meaningful conclusion from this distribution in current stage. While further investigation will be conducted in the future, the average value of each parameters $(a=14.5, b=1.81, c=9.56)$ were used for the prediction of material distribution in current study. 


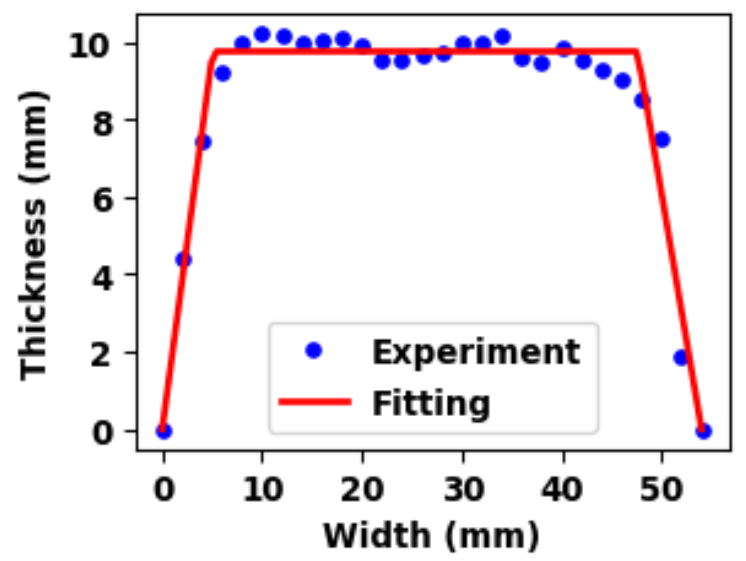

Figure 9 The comparison between experimental thickness and fitted three straight lines model of experiment group $\mathrm{E}$ with $150 \mathrm{~mm} / \mathrm{s}$ nozzle travel speed.

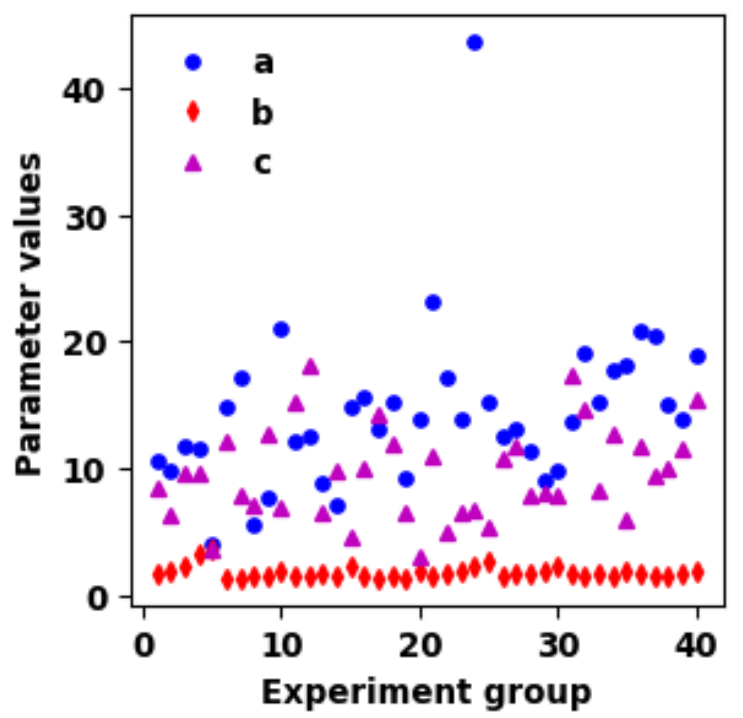

Figure 10 Fitted parameter for filament thickness distribution

\section{Verification of Empirical Model}

Validation experiments were designed to verify the proposed empirical model. The pumping rate, air inject pressure, nozzle standoff distance of validation experiments were 900 rpm, $0.75 \mathrm{bar}$, and $70 \mathrm{~mm}$, respectively. The nozzle travel path and speed were the same as all other experiment groups as shown in Figure 4. The same image analysis process was adopted, and corresponding material distribution has been compared with the predicted results of empirical model as shown in Figure 11. As can be seen in Figure 11, the proposed empirical model can well predict the material distribution of 3D spray cementitious material printing when the travel speed is 50, 100, and $250 \mathrm{~mm} / \mathrm{s}$. However, the predicted maximum filament widths are not accurate for cases when travel speed is 150 and $200 \mathrm{~mm} / \mathrm{s}$. 

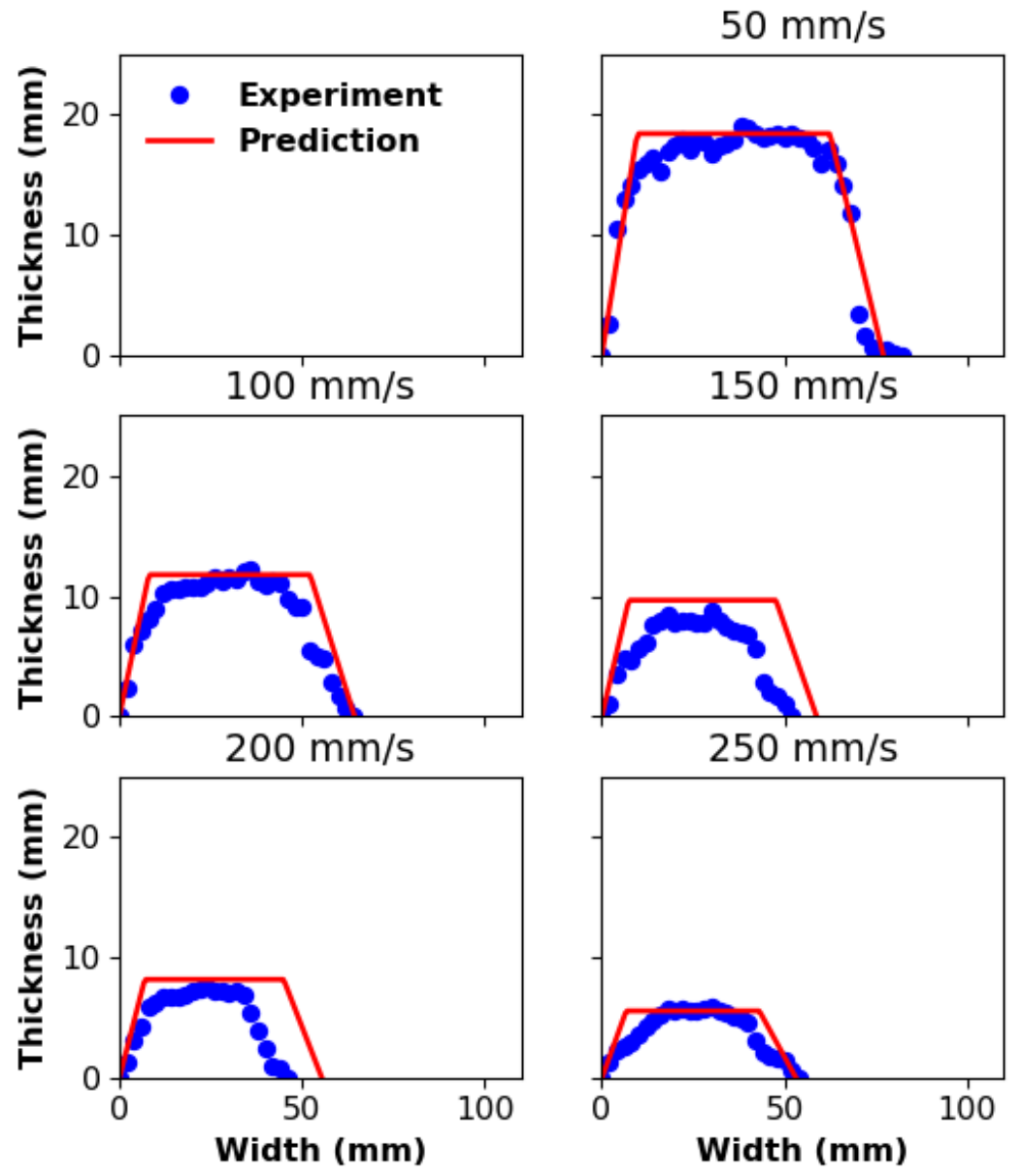

Figure 11 Comparison between validation experimental and predicted material thickness distribution

\section{Conclusion}

In this paper, the material distribution in 3D spray cementitious material printing was investigated. With the adoption of robotic arm control, effects of four printing parameters (i.e. cementitious material flow rate, air flow rate, nozzle travel speed and standoff distance) to material distribution were studied. The experimental results showed that the increases of pumping speed or standoff distance increases the maximum filament width, the increase of nozzle travel speed decreases the maximum filament width, the change of air inject pressure has negligible effect on material distribution. When the ratio between pumping speed and nozzle travel speed decrease to under some specific value, which requires further study, the sprayed filament density will decrease and thus, the cross section area will only decrease slightly.

Based on the experimental material distribution results, an empirical model was proposed to describe the material distribution in 3D spray cementitious material printing. Different from the conventional concrete spray process, the influence of moving nozzle and 
extra brought by air flow with projected material have been taken into consideration. This empirical model predicts that the maximum filament width is linearly related to the product of standoff distance and the square root of the ratio of pumping speed and nozzle travel speed, then the material distribution is described by an empirical trapezoid shape model. The verification experiments show that this empirical model can predict the maximum filament width and material distribution in a reasonable level. In the future, this empirical model will be improved and used in planning of 3D spray cementitious material printings.

\section{Acknowledgement}

This research is supported by the National Research Foundation, Prime Minister's Office, Singapore under its Medium-Sized Centre funding scheme, Singapore Centre for 3D Printing and Sembcorp Design \& Construction Pte Ltd.

\section{Reference}

[1] C. K. Chua and K. F. Leong, 3D Printing and Additive Manufacturing: Principles and Applications: World Scientific Publishing Co Inc, 2017.

[2] B. Khoshnevis, "Automated construction by contour crafting-related robotics and information technologies," Automation in Construction, vol. 13, pp. 5-19, 2004.

[3] S. Lim, R. A. Buswell, T. T. Le, S. A. Austin, A. G. F. Gibb, and T. Thorpe, "Developments in construction-scale additive manufacturing processes," Automation in Construction, vol. 21, pp. 262-268, 2012.

[4] C. Gosselin, R. Duballet, P. Roux, N. Gaudillière, J. Dirrenberger, and P. Morel, "Large-scale 3D printing of ultra-high performance concrete-a new processing route for architects and builders," Materials and Design, vol. 100, pp. 102-109, 2016.

[5] C. Jeffrey. (2014). Team of 3D-printing "Minibuilder" robots print large-scale structures on site. Available: https://newatlas.com/minibuilder-robots-3d-print-largescale-structures/32573/

[6] T. T. Le, S. A. Austin, S. Lim, R. A. Buswell, A. G. F. Gibb, and T. Thorpe, "Mix design and fresh properties for high-performance printing concrete," Materials and Structures, vol. 45, pp. 1221-1232, 2012.

[7] B. Khoshnevis, X. YUAN, B. Zahiri, J. Zhang, and B. Xia, "Deformation Analysis of Sulfur Concrete Structures Made by Contour Crafting," in AIAA SPACE 2015 Conference and Exposition, Pasadena, USA, 2015, p. 4452.

[8] A. Perrot, D. Rangeard, and A. Pierre, "Structural built-up of cement-based materials used for 3D-printing extrusion techniques," Materials and Structures, vol. 49, pp. 12131220, 2016.

[9] Y. Zhang, Y. Zhang, G. Liu, Y. Yang, M. Wu, and B. Pang, "Fresh properties of a novel 3D printing concrete ink," Construction and Building Materials, vol. 174, pp. 263-271, 2018.

[10] Y. Weng, M. Li, M. J. Tan, and S. Qian, "Design 3D printing cementitious materials via Fuller Thompson theory and Marson-Percy model," Construction and Building Materials, vol. 163, pp. 600-610, 2018.

[11] B. Panda, S. C. Paul, L. J. Hui, Y. W. D. Tay, and M. J. Tan, "Additive manufacturing of geopolymer for sustainable built environment," Journal of Cleaner Production, vol. 167, pp. 281-288, 2017.

[12] D. G. Soltan and V. C. Li, "A self-reinforced cementitious composite for building-scale 3D printing," Cement and Concrete Composites, vol. 90, pp. 1-13, 2018. 
[13] Y. Weng, M. Li, M. J. Tan, L. He, and S. Qian, "3D Printable High Performance Fiber Reinforced Cementitious Composites for Large-scale Printing," in Proceeding of the 3rd International Conference on Progress in Additive Manufacturing, Singapore, 2018, pp. 19-24.

[14] W. Lao, M. Li, L. Masia, and M. J. Tan, "Approaching Rectangular Extrudate in 3D Printing for Building and Construction by Experimental Iteration of Nozzle Design," in Proceedings of Solid Freeform Symposium, Austin, TX, USA, 2017, pp. 2612-2623.

[15] F. Bos, R. Wolfs, Z. Ahmed, and T. Salet, "Additive manufacturing of concrete in construction: potentials and challenges of 3D concrete printing," Virtual and Physical Prototyping, vol. 11, pp. 209-225, 2016.

[16] B. Panda, S. C. Paul, N. A. N. Mohamed, Y. W. D. Tay, and M. J. Tan, "Measurement of tensile bond strength of 3D printed geopolymer mortar," Measurement, vol. 113, pp. 108-116, 2018.

[17] ACI Committee 506, "Guide to shotcrete / reported by ACI Committee 506 (ACI 506R05)," ed. Detroit, USA: American Concrete Institute, 2005.

[18] B. Lu, M. Li, S. Qian, K. F. Leong, and M. J. Tan, "Develop Cementitious Materials Incorporating Fly Ash Cenosphere for Spray-based 3D Printing," in Proceedings of the 3rd International Conference on Progress in Additive Manufacturing, Singapore, 2018, pp. 38-43.

[19] C. ASTM, "1437-01. Standard test method for flow of hydraulic cement mortar," ASTM International, Pennsylvania, 2001.

[20] N. Ginouse and M. Jolin, "Mechanisms of placement in sprayed concrete," Tunnelling and Underground Space Technology, vol. 58, pp. 177-185, 2016. 